\title{
Follow-up study of disability among elderly patients discharged from hospital with exacerbations of chronic bronchitis
}

\author{
HEDLEY PEACH, MS PATHY \\ From the Department of Geriatric Medicine, University Hospital of Wales, Cardiff
}

ABSTRACT Chronic bronchitis is a common reason for admitting an old person to hospital. Government statistics measure the impact of admission only in terms of mortality. A follow-up study of disability among the elderly admitted to hospital with an exacerbation of chronic bronchitis is described. One month after discharge about $30 \%$ of patients were unable to walk as far on the flat or climb as many steps as they did before admission and $90 \%$ were unable to do all previous household chores or social activities. After a further two months, although the proportion of patients unable to do all previous household chores or social activities had decreased significantly the proportion with restricted ambulation or ability to climb stairs had not decreased. The proportion of patients admitting to anxiety or depression and being dissatisfied with their progress also remained high. We conclude that there is a need for graduated rehabilitation programmes, which have been shown to increase the walking distance of elderly bronchitics, to be extended to cover all aspects of disability and for home rehabilitation to become an integral part of the care of all elderly bronchitics discharged from hospital.

The natural history of chronic bronchitis is one of increasing episodes of cough, sputum, wheeze, and dyspnoea commonly following chest infections from which the patient takes progressively longer to recover and is left with residual symptoms which become progressively more troublesome. " "Chronic bronchitis and emphysema" is one of the most common conditions with which elderly patients are admitted to hospital. Seventy-five per cent of the patients are admitted as emergencies during an acute exacerbation and $50 \%$ usually have no other serious medical condition. ${ }^{2}$ The success of such hospital admissions is only measured in government statistics in terms of mortality. Fifty per cent of elderly patients admitted during the acute episode survive to be discharged. However, no statistics are routinely available about the impact which admission to hospital with an acute exacerbation of chronic bronchitis has on the everyday life of elderly patients even though the average length of hospital stay in uncomplicated cases is 24 days. $^{2}$ We describe a followup study of disability and psychological impairment

Address for reprint requests: Dr Hedley Peach, Department of Community Medicine, St Thomas's Hospital Medical School, London SE1 7EH. after discharge from geriatric wards after an acute exacerbation of chronic bronchitis.

\section{Methods}

We have used the definitions of impairment, disability, and handicap devised by WHO ${ }^{3}$ In this classification "impairments" are disturbances in body structure or functioning that may arise from birth, accidents or disease and affect any part of the body. "Disabilities" are limitations in the performance of functions customarily expected of the body and its parts, or restrictions in activity consequent upon impairment. "Handicaps" are the disadvantages experienced by impaired or disabled people who do not conform to the expectations of the social group to which they belong.

There are three methods by which disability can be identified and measured: clinical assessment of performance; standard tests of performance conducted by a trained observer; and detailed questioning of the person about his or her level of daily performance, using a self-administered or interview-administered questionnaire. Because disability and psychological impairment are common among the elderly, a survey to identify and measure these as a consequence of 
admission to a geriatric ward after an acute exacerbation of chronic bronchitis must compare the degree of disability and impairment after discharge with that before admission to hospital. An assessment of the latter can only be obtained by questioning the patient about his or her previous level of performance. We therefore decided to use a questionnaire to identify and measure the increase in disability after discharge. Other workers have shown that questionnaires can give reliable and valid assessments of disability. 45

The survey was conducted in three stages. During the first and third stages patients completed a postal screening questionnaire in their own homes at the end of the first and third month after discharge from hospital. The questionnaire contained seven stemquestions designed to reveal changes in the important aspects of psychological well-being (degree of anxiety and frequency of depression about having bronchitis), ability to perform specified activities of daily living (namely mobility, ambulation, climbing stairs), and any limitation in doing household chores or social activities because of the bronchitis. There were several possible answers to each question covering the range of disability or psychological impairment. For each question, points were assigned to the different answers according to an equal interval scale, zero points being scored for the most severe degree of disability or psychological impairment.

During the second stage the patients completed a semi-structured questionnaire covering the reasons for being anxious or depressed, having difficulty with daily living activities or having limitations in performing household chores or social activities.

The reproducibility of the screening questionnaire was assessed in the following way. A sample of patients who had completed the screening questionnaire did so again within two weeks and the scores obtained were compared. At the time of completing the first questionnaire the patients themselves were unaware that they would be completing the questionnaire again or that they would be asked to complete a follow-up questionnaire two months later.

\section{Results}

Fifty consecutive patients who had been discharged from a geriatric medical ward of a Cardiff hospital after an exacerbation of chronic bronchitis were studied. Thirty of the patients were men and 20 were women. Thirty per cent were over 75 years old. Six patients had had a previous admission with an acute exacerbation of chronic bronchitis.

The medical and nursing routines were similar for all patients. On the day of admission they were permitted to rest in bed in any position of comfort, to

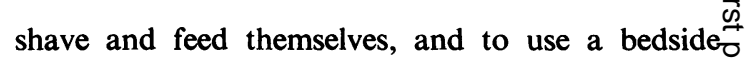
commode. Progressive systematic mobilisation was started over the next two to 28 days. All patients $\overline{\bar{n}}$. were discharged between two and four weeks afterब admission and were aware of the diagnosis before discharge.

\section{FIRST STAGE QUESTIONNAIRE}

Forty-seven replies were received to the first mailing $\vec{\omega}_{\mathscr{\omega}}$ of the screening questionnaire. Among the three who failed to reply one had died, one had had a stroke, $\underset{\omega}{\times}$ and one had been readmitted to hospital. The num- $-\circ$ ber of replies represented a $100 \%$ response from $G$ those able to reply and we did not repeat the mailing.

The frequency of the various responses to theo questions are shown in tables 1 to 3 . A third of the patients had assessed their progress since discharge from hospital as "poor" or only "fair". About a halto of the patients admitted to feelings of anxiety orc depression about having had a recent exacerbation $\overrightarrow{\overrightarrow{0}}$ of their chronic bronchitis. The number of patient 500 walking with difficulty, unable to walk a hundred: yards on the flat, or climb to the top of their stairso had increased by approximately $25 \%$ after discharge from hospital.

Table 1 Psychological impairment among patients onex and three months after discharge

\begin{tabular}{|c|c|c|}
\hline & \multicolumn{2}{|c|}{ Number of patients } \\
\hline & One month & Three month \\
\hline $\begin{array}{l}\text { Degree of anxiety } \\
\text { Very anxious } \\
\text { Anxious } \\
\text { Fairly anxious } \\
\text { Not anxious }\end{array}$ & $\begin{array}{c}10(21 \%) \\
0 \\
10(21 \%) \\
27(63 \%)\end{array}$ & $\begin{array}{c}9(21 \%) \\
0 \\
10(23 \%) \\
24(56 \%)\end{array}$ \\
\hline $\begin{array}{l}\text { Frequency of depression } \\
\text { Always } \\
\text { Often } \\
\text { Sometimes } \\
\text { Never }\end{array}$ & $\begin{array}{c}10(21 \%) \\
0 \\
17(36 \%) \\
20(43 \%)\end{array}$ & $\begin{array}{l}9(21 \%) \\
0 \\
16(37 \%) \\
18(42 \%)\end{array}$ \\
\hline
\end{tabular}

Table 2 Mobility of patients before admission and one month after discharge (from first stage questionnaire)

\begin{tabular}{|c|c|c|}
\hline \multirow[t]{2}{*}{ Mobility } & \multicolumn{2}{|l|}{ Number of patients } \\
\hline & Before admission & $\begin{array}{l}\text { One month } \\
\text { after discharge }\end{array}$ \\
\hline $\begin{array}{l}\text { Confined to chair } \\
\text { Walking with difficulty } \\
\text { Walking }\end{array}$ & $\begin{array}{l}0 \\
9(19 \%) \\
38(81 \%)\end{array}$ & $\begin{array}{l}7(15 \%) \\
20(43 \%) \\
20(43 \%)\end{array}$ \\
\hline $\begin{array}{l}\text { Distance on flat } \\
\text { Less than } 100 \text { yards } \\
\text { More than } 100 \text { yards }\end{array}$ & $\begin{array}{l}10(21 \%) \\
37(81 \%)\end{array}$ & $\begin{array}{l}21(45 \%) \\
26(55 \%)\end{array}$ \\
\hline $\begin{array}{l}\text { Climbing stairs } \\
\text { Top } \\
\text { Three-quarters } \\
\text { Half-way } \\
\text { One-quarter } \\
\text { Not at all }\end{array}$ & $\begin{array}{l}20(43 \%) \\
11(23 \%) \\
7(15 \%) \\
0 \\
9(19 \%)\end{array}$ & $\begin{array}{c}9(19 \%) \\
13(28 \%) \\
10(21 \%) \\
4(9 \%) \\
11(23 \%)\end{array}$ \\
\hline
\end{tabular}


Table 3 Proportion of previous household chores and social activities done one and three months after discharge

\begin{tabular}{lcc}
\hline & \multicolumn{2}{l}{ Number of patients } \\
\cline { 2 - 3 } & One month & Three months \\
\hline Household chores & & \\
All chores & 0 & $15(35 \%)$ \\
Three-quarters & $3(6 \%)$ & $14(33 \%)$ \\
Half & $7(15 \%)$ & $2(5 \%)$ \\
One-quarter & $12(26 \%)$ & $1(2 \%)$ \\
None & $25(58 \%)$ & $11(25 \%)$ \\
Social activities & & \\
All activities & $9(19 \%)$ & $15(35 \%)$ \\
Three-quarters & $7(15 \%)$ & $5(12 \%)$ \\
Half & $8(17 \%)$ & $5(12 \%)$ \\
One-quarter & $11(23 \%)$ & $9(21 \%)$ \\
None & $12(26 \%)$ & $9(21 \%)$ \\
\hline
\end{tabular}

Eighty per cent and $100 \%$ of the patients respectively were unable to do the number of social activities and household chores which they could do before admission. Thirty-eight of the patients said that their determination to get better was at least "good".

There was no significant difference between the scores obtained by men and women or by the different age groups. The scores obtained by the six who had had a previous admission (mean score 17) were lower than the scores by those who had not had a previous admission (mean score 24).

Among the twenty-five patients who had completed the screening questionnaire again within two weeks of the first stage, correlation between the total scores was good $(r=0.8)$. There was also a good correlation between individual question scores $(r$ never less than $\mathbf{0 \cdot 7}$ ).

\section{SECOND STAGE QUESTIONNAIRE}

Twenty-three patients had no other serious illness at the time of their hospital admission. The remaining 24 reported chronic joint disease and angina.

Of the patients who admitted to being anxious or depressed about their bronchitis, 10 were unable to give a reason for this. The most common reasons cited by the remaining patients were a slow recovery and being unable to walk on the flat or climb stairs. Breathlessness and fatigue were the most common reasons for being restricted in walking on the flat, climbing stairs, in doing household chores, or taking part in social activities.

THIRD STAGE QUESTIONNAIRE

Forty-three patients replied to the first mailing of the questionnaire sent three months after discharge from hospital. This represented an $87 \%$ response from those who had received the first questionnaire and the mailing was not repeated.

When the total scores obtained by the patients in the first and third stages were compared 24 had im- proved (mean improvement $4 \cdot 3$ with a range of 1 to 13 points) and 12 had deteriorated further.

The frequency of positive responses to the different questions is shown in tables 1 to 4 . There was no significant increase between the first and third stage results in the proportion of patients not reporting any anxiety or depression about their bronchitis, being able to walk without difficulty, being able to walk 100 yards on the flat, or being able to climb to the top of their stairs. However, the proportion of patients being able to do all the household chores and social activities they had done before their exacerbation of bronchitis had increased from zero and $20 \%$ respectively to about $30 \%$.

Table 4 Mobility of patients before admission and three months after discharge (from third stage questionnaire)

\begin{tabular}{lcc}
\hline Mobility & \multicolumn{2}{c}{ Number of patients } \\
\cline { 2 - 3 } & Before admission & $\begin{array}{c}\text { Three months } \\
\text { after discharge }\end{array}$ \\
\hline Confined to chair & 0 & $3(7 \%)$ \\
Walking with difficulty & $6(14 \%)$ & $20(47 \%)$ \\
Walking & $37(86 \%)$ & $20(47 \%)$ \\
Distance on flat & $7(16 \%)$ & $19(44 \%)$ \\
Less than 100 yards & $36(83 \%)$ & $24(56 \%)$ \\
More than 100 yards & $20(47 \%)$ & $8(18 \%)$ \\
Climbing stairs & $10(23 \%)$ & $9(21 \%)$ \\
Top & $6(14 \%)$ & $12(28 \%)$ \\
Three-quarters & 0 & $4(9 \%)$ \\
Half-way & $7(16 \%)$ & $10(23 \%)$ \\
One-quarter & & \\
Not at all & & \\
\hline
\end{tabular}

\section{Discussion}

Since chemoprophylaxis has little effect on the decline of $F E V_{1}$ over a period of several years, ${ }^{6}{ }^{7}$ the emphasis in the care of patients with chronic bronchitis should be on reducing disability and handicap. One possible line of attack is to try to minimise the stepwise reduction in dependency which follows acute exacerbations of chronic bronchitis. It has been known for some time that although there is good agreement between lung function tests and reported disability in terms of groups, in terms of individuals the variation is wide. ${ }^{8}$ This is because the translation of an impairment into disability depends on many factors, such as the patients' perception of disease and socioeconomic factors and not just the degree of impairment. ${ }^{9}$ Therefore, a proportion of the disability which follows an acute exacerbation of chronic bronchitis might be ameliorated by an appropriate programme of rehabilitation.

Although most hospitals to which elderly patients with an acute exacerbation of chronic bronchitis are admitted nowadays have a programme of active rehabilitation, this is usually aimed at early dis- 
charge. Patients and relatives are not given programmes with which to continue the rehabilitation at home. There are two reasons for this: firstly, the failure of doctors to appreciate the prevalence of disability among their elderly bronchitics at homeprobably because there is no simple method of measuring this among elderly patients in the community; and secondly, pessimism about what rehabilitation can achieve.

We have devised a simple and reproducible postal questionnaire which can be used to screen for disability among elderly bronchitics at home. Despite the almost universally good determination to recover, one month after discharge about $25 \%$ of our patients were unable to walk as far on the flat or climb as many steps as they did before admission and most patients were unable to do all the household chores or social activities they had previously done. After a further two months, although the proportion of patients able to do all previous household chores or social activities had increased, the proportion with restricted ambulation or ability to climb stairs had not decreased. The proportion of patients admitting to anxiety or depression and being dissatisfied with their progress also remained high. Our survey shows that there is considerable psychological impairment and disability among elderly patients for several months after being discharged from hospital with an exacerbation of chronic bronchitis and that there is a need for rehabilitation to continue after the patient has gone home.

The pessimism about what rehabilitation programmes can achieve is probably unjustified. We have found that the severe respiratory cripple can improve his exercise tolerance considerably with a walking frame provided that its height allows his upper limbs to be straight when he places his full weight on the aid, he is assured that the purpose of the aid is to assist his "chest" muscles to function more effectively, and he is taught to breathe out fully through pursed lips between each pace. ${ }^{10}$ At home the patient tries to achieve specific targets of known distances, such as length of his garden, distance to a neighbour's house, phone box, corner shop, or the pub. Instead of using a walking aid, Sinclair and Ingram devised a programme of daily-12-minute walks and simple stair climbing exercises to be performed at home and, once a week, under supervision in hospital. In a controlled trial, this programme produced a $24 \%$ increase in the walking distance of elderly bronchitics after eight to 12 months. ${ }^{11}$

Our survey shows that as well as ambulatory restrictions, elderly bronchitics have difficulty performing household chores and social activities. Theoretically, these disabilities should be as amenable to rehabilitation as distance walked for it was in these areas of life that Hyman found the greatesto disparity between severity of impairment and dys-흥 function. ${ }^{9}$ It is possible that the benefits of a gradu- $\overline{-\bar{D}}$ ated walking programme will spread over to these $\mathbb{\Phi}_{0}$ other aspects of disability. A controlled trial musto establish whether this is so. In any event, it should be ${ }^{\infty}$ possible to devise a goal-orientated rehabilitation. programme for household chores and social activities $\overrightarrow{\vec{\omega}}$ similar to that used by us for restricted ambulation. $\omega$

For some elderly bronchitics home rehabilitation $\vec{x}$ will be impracticable because of the lack of relatives, $\dot{\omega}$ friends, or neighbours to supervise and encourage. \% These patients could attend a day hospital but the improvement described by Sinclair and Ingram took of eight to 12 months, which is a long time to keepo bringing an old person up to a day hospital. An alternative approach would be to make use of $\square$ voluntary home aides. Several hospitals already haveco after-care schemes established by Age Concernos England in which a voluntary commitment is used to $\vec{A}$ support the professional health and personal social $œ$ services when an old person arrives home from. hospital and is at his most vulnerable. ${ }^{12-14}$ At the moment, the volunteers only perform services on the old person's behalf. Even so, Nielsen et al found that $\bar{\partial}$ patients receiving home aides had significantly higher "contentment with life" scores than controls. ${ }^{15} \stackrel{\square}{2}$ By improving an elderly bronchitic's outlook on life, $\overrightarrow{\vec{O}}$ home aide schemes may incidentally reduce the 3 degree of disability. However, we suggest that if home aide schemes are to be established nationwide, the aides deliberately set out to restore the bronchitic to his pre-hospital level of independence with a pre- 을 designed training programme. With experience, $\stackrel{\otimes}{x}$ early discharge programmes and after-care schemes 윽 could be combined in a single rehabilitation programme for elderly bronchitics.

\section{References}

${ }^{1}$ Crofton J, Douglas A. Respiratory diseases. Oxford: Blackwell Scientific Publications, 1975:337.

2 Department of Health and Social Security, Office of Popu- $\widetilde{S}$ lation Censuses and Surveys, Welsh Office. Hospital $N$ Inpatient Enquiry-Main Tables. Series MB4 number 7. O London: HMSO, 1976.

${ }^{3}$ World Health Organisation. International classification of $\sigma$ impairments, disabilities and handicap. Wood PHN, ed. Geneva: World Health Organisation, 1980.

${ }^{4}$ Bennett AE, Garrad J, Halil T. Chronic disease and dis- $\mathbb{D}$ ability in the community: a prevalence study. $\mathrm{Br}$ Med $J \stackrel{\text { ? }}{+}$ $1970 ; 3: 762-4$.

${ }^{5}$ Farrad J, Bennett AE. A validated interview schedule for $\overrightarrow{0}$ use in population surveys of chronic disease and dis- $\vec{D}$ ability. Br J Prev Soc Med 1971;25:97-104.

- MRC Working Party. Value of chemoprophylaxis and $\mathbb{Q}$ chemotherapy in early bronchitis. Br Med J 1966;1: 음 1317-22.

7 Johnston RN, McNeill RS, Smith DH et al. Five-year $ᄋ$ winter chemoprophylaxis for chronic bronchitis. Br Med 
$J$ 1969;4:265-9.

${ }^{8}$ Silver HM. Pulmonary function and therapy in disability applicants. JAMA 1965;191:1059-63.

${ }^{9}$ Hyman MD. Disability and patients' perceptions of preferential treatment: some preliminary findings. J Chronic Dis 1971;24:329-42.

10 Pathy MS. Exercise training for bronchitics. Geriatr Med 1980;10:4-5.

${ }^{11}$ Sinclair DJM, Ingram CG. Controlled trial of supervised exercise training in chronic bronchitis. $\mathrm{Br}$ Med J 1980; $1: 519-21$.
12 Walton SJ. Paper presented at MIND annual conference, 1978.

13 Age Concern Gateshead. Annual Report. Gateshead: Age Concern, 1979.

14 Age Concern Leicestershire. Annual Report. Leicester: Age Concern, 1979.

15 Nielsen M, Blenker M, Bloom M, Downs T, Beggs $H$. Older persons after hospitalization: a controlled study of home aide service. Am J Public Health 1972;62: 1094-101. 